\title{
2017 Fact Sheet \\ Childhood Agricultural Injuries in the U.S.
}

National Children's Center

for Rural and Agricultural Health and Safety

\section{Population at Risk}

Farms $\quad$ - In 2016, there were approximately 2.06 million farms in the United States. ${ }^{1}$

Children - About 893,000 youth lived on farms in 2014 and more than half (51\%) worked on their farm. ${ }^{2}$

- More than 265,600 non-resident youth were hired in agriculture in $2014 .^{2}$

- Approximately $23,883,000$ youth visited farms in $2014 .^{2}$

\section{Toll of Childhood Agricultural Injuries}

Deaths - Every three days, a child dies in an agriculture-related incident.*

- Of the leading sources of fatalities among all youth, $25 \%$ involved machinery,

$17 \%$ involved motor vehicles (includes ATVs), and $16 \%$ were drownings. ${ }^{3}$

- For working youth, tractors were the leading source of fatalities followed by ATVs. ${ }^{4}$

Nonfatal - Every day, about 33 children are injured in agriculture-related incidents.**

Injuries - In 2014, an estimated 7,469 household ${ }^{\dagger}$ youth were injured on a farm and $60 \%$ of them were not working when the injury occurred. ${ }^{5}$

- An estimated 738 hired youth were injured on farms in $2014 .^{5}$

- Approximately 3,735 visiting youth were injured on farms in $2014 .^{5}$

- Vehicles were the leading source of injury for household working youth. ${ }^{5}$

There is no central database on childhood agricultural injuries. This fact sheet draws from the best available data.

- Animals were the leading source of injury for both household non-working youth and visitors. ${ }^{5}$

\section{Injury Trends}

- While overall numbers of farm injuries are declining, injuries to household youth have held steady. ${ }^{5}$

- Among household youth on farms, injury rates increased in 2014 for youth 10-19 years. ${ }^{5}$

- From 2003 to 2010, among workers younger than 16 years, the number of worker fatalities in agriculture was consistently higher than in all non-agricultural industries combined. ${ }^{6}$
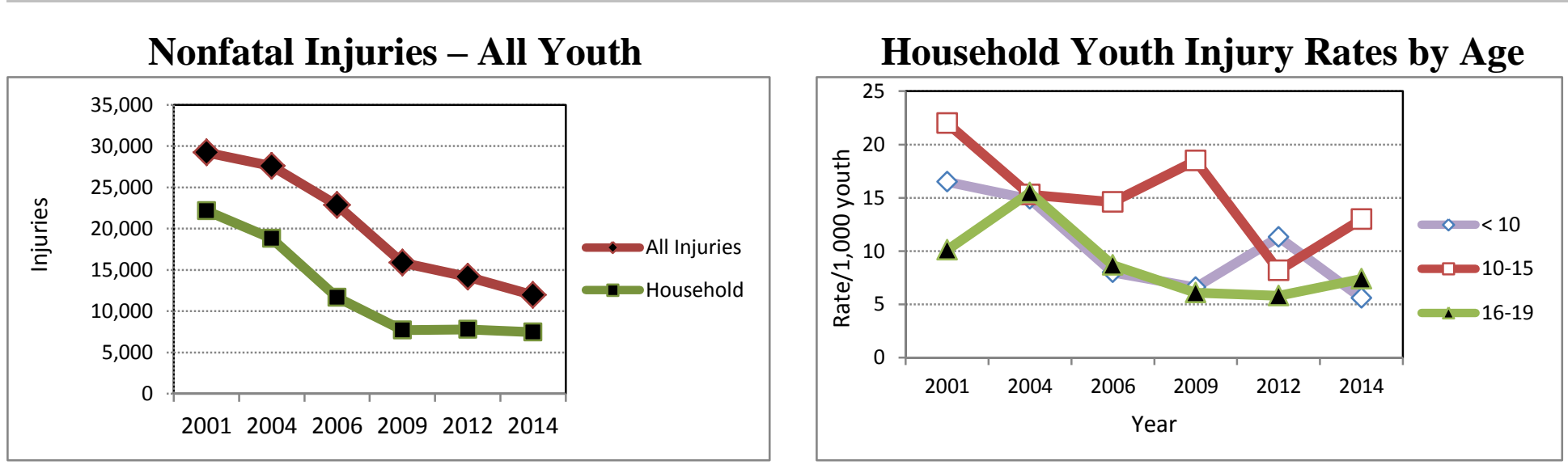

Note: Data from the Childhood Agricultural Injury Survey (CAIS) does not include injuries to contract laborers. For more detailed child agricultural injury data, go to http://www.cdc.gov/niosh/topics/childag/.

*From reported 115 agriculture-related deaths annually from 1995 to $2000 .^{3}$

**From estimated 11,942 injuries in $2014 .^{5}$

${ }^{\dagger}$ Household youth are youth who live on a farm 


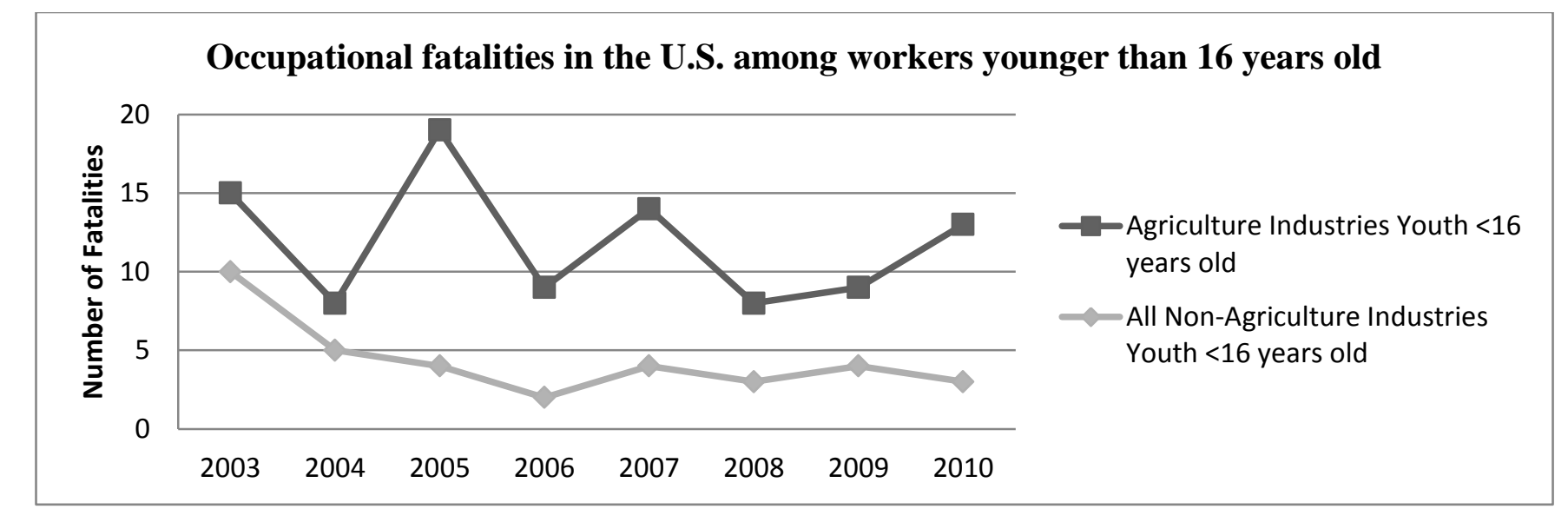

Reprinted with permission from Wright et al (2013). ${ }^{6}$

\section{Economic Data}

Nonfatal Injuries $\quad$ Youth agricultural injuries cost society an estimated \$1 billion per year (in 2005 dollars). ${ }^{7}$

Fatalities

$$
\text { Youth agricultural deaths cost society an estimated \$420 million per year (in } 2005 \text { dollars). }{ }^{7}
$$

Injury Prevention Strategies and Resources

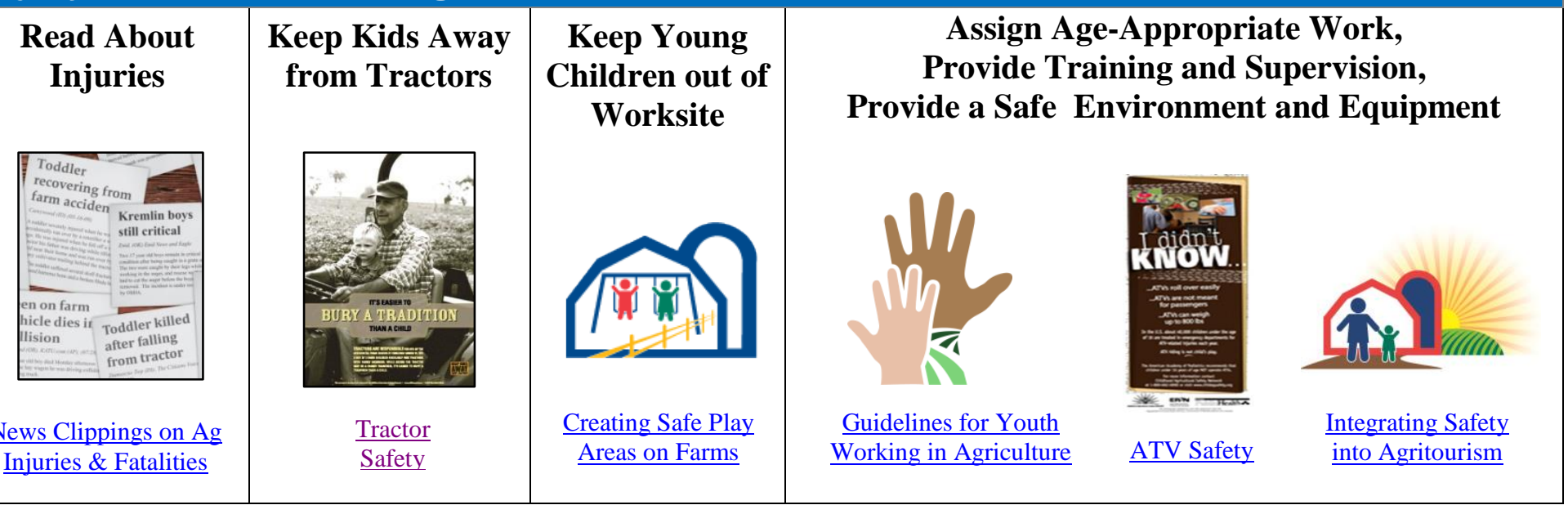

\section{References}

1. USDA, NASS publications: Farms and Land in Farms, 2016 Summary, February 2017. Available at: http://usda.mannlib.cornell.edu/usda/current/FarmLandIn/FarmLandIn-02-17-2017.pdf

2. Childhood Agricultural Injury Survey (CAIS) Results. Available at: https://www.cdc.gov/niosh/topics/childag/cais/demotables.html

3. Goldcamp M, Hendricks KJ, Meyers JR. (2004). Farm Fatalities to youth 1995-2000: A comparison by age groups. Journal of Safety Research. Vol. 35(2): 151-157.

4. Hendricks KJ, Hard DJ. (2014). Working youth on farms. Unpublished presentation at the National Youth Farm and Ranch Symposium, Louisville, KY, October 27-28.

5. NIOSH (2016). Analyses of the 2014 Childhood Agricultural Injury Survey (CAIS). Morgantown WV: U.S. Department of Health and Human Services, Public Health Service, Centers for Disease Control and Prevention, National Institute for Occupational Safety and Health, Division of Safety Research. Unpublished.

6. Wright S, Marlenga B, Lee BC (2013). Childhood agricultural injuries: An update for clinicians. Curr Probl Pediatr Adolesc Health Care. Vol. 43(2): 20-44.

7. Zaloshnja E, Miller TR, Lawrence BA (2012). Incidence and Cost of Injury Among Youths in Agricultural Settings, United States, 2001-2006 Pediatrics. Vol. 129(4): 728-734.

For more information contact:

National Children's Center for Rural and Agricultural Health and Safety

Phone: 800-662-6900

Email: nccrahs@mcrf.mfldclin.edu

Website: http://www.marshfieldresearch.org/nccrahs 